\title{
OUTCOME OF HYPERTENSIVE DISORDERS IN PREGNANCY
}

\author{
Anjum Kekhashan ${ }^{1}$, Asuri Shanti Sri²
}

${ }^{1}$ Assistant Professor, Department of Obstetrics and Gynaecology, Princess Esra Hospital, Deccan College of Medical Sciences, Hyderabad. ${ }^{2}$ Associate Professor, Department of Obstetrics and Gynaecology, Princess Esra Hospital, Deccan College of Medical Sciences, Hyderabad.

\section{ABSTRACT}

\section{BACKGROUND}

Hypertensive disorders in pregnancy are associated with severe maternal obstetric complications and are a leading contributor to maternal mortality. Hypertensive disorders in pregnancy seriously endanger the safety of the mother and foetus. Hypertensive disorders in pregnancy has been associated with adverse maternal and foetal outcome yet very few studies have this disease in India. This prospective study is to know the incidence of the disorders and associated risk factors and to assess the maternal and perinatal outcome in cases of hypertensive disorders in pregnancy.

The purpose of this study is,

1. To study the incidence and to analyse the disease and risk factors associated with the disorders.

2. To assess the maternal and perinatal outcome of hypertensive disorders in pregnancy in our institute.

\section{MATERIALS AND METHODS}

A prospective study of women with hypertensive disorders in pregnancy was undertaken from February 2014 to January 2015 in the Department of Obstetrics and Gynaecology at Princess Esra Hospital. Analysis was carried out on 140 patients. Patients were further classified according to the National High Blood Pressure Education Working Group (NHBPEP) (2000) as having Gestational hypertension (83 cases), mild preeclampsia (38 cases), severe preeclampsia (13 cases), eclampsia (6 cases); 40 healthy pregnant non-hypertensive women were enrolled into the study as control.

\section{RESULTS}

The most common disorder was oedema, seen in $85.7 \%$ of cases. Proteinuria was also relatively common, $25.14 \%$ of patients with proteinuria of $\geq 300 \mathrm{mg} / 24$ hours, $9.28 \%$ with proteinuria of $\geq 2 \mathrm{~g} / 24$ hours. Central nervous system involvement was observed in $7.1 \%$ of cases, elevated bilirubin levels in $1.4 \%$ of cases, visual symptoms in $2.8 \%$, vaginal bleeding in $6.4 \%$ and HELLP (haemolysis, elevated liver enzymes and low platelet count) syndrome was reported in $0.7 \%$. Stillbirths occurred in $3.5 \%$ of cases and overall perinatal mortality observed in $7.8 \%$ of cases.

\section{CONCLUSION}

Hypertensive disorder pregnant women were more prone to the adverse maternal and foetal outcome than in a nonhypertensive pregnant women, but in our study we have observed a decreasing trend when compared with that reported in other studies, which might be due to the increased number of hospital deliveries that has been occurred in our study, whereas complete prenatal care is associated with a better maternal and foetal outcome in HDP.

\section{KEYWORDS}

Pregnancy, Hypertension.

HOW TO CITE THIS ARTICLE: Kekhashan A, Sri AS. Outcome of hypertensive disorders in pregnancy. J. Evolution Med. Dent. Sci. 2016;5(83):6176-6181, DOI: 10.14260/jemds/2016/1396

\section{BACKGROUND}

Hypertensive disorders complicating pregnancy is the most common complication that occurs in pregnancy. The incidence varies in different populations, different races and is affected by the definitions used. Mostly hypertensive disorders are seen in nulliparous women, teenage pregnancy or elderly women and race. In India in 2006 to 2007, the incidence of hypertensive disorders in pregnancy was $5.38 \%$, while the incidence accounted for preeclampsia is $44 \%$, eclampsia is

Financial or Other, Competing Interest: None.

Submission 27-09-2016, Peer Review 08-10-2016,

Acceptance 11-10-2016, Published 15-10-2016.

Corresponding Author:

Dr. Anjum Kekhashan,

\#6-1-347, Mehboob Manzil,

Khairatabad, Hyderabad-500004,

Telangana.

E-mail: dranjumkehkashan@gmail.com

DOI: $10.14260 /$ jemds/2016/1396
$40 \%$ and HELLP syndrome is about $7 \%$ of complications respectively. ${ }^{1}$ Maternal and perinatal deaths have been reported in $5.5 \%$ and $37.5 \%$ deleveries. ${ }^{1}$ Hypertensive disorders in pregnancy comprises of preeclampsia and eclampsia. Preeclampsia is a multisystem disorder of unknown aetiology that affects $4 \%-5 \%$ of pregnancies, 2,3 whereas the incidence of eclampsia is $0.3 \%-0.9 \%$ and it has maternal mortality rate of $0.5 \%-10 \% .4$

The pathogenesis of hypertensive disorders in pregnancy is not completely clear. Although, the exact mechanisms which lead to this disorder is not clear, but several factors are known to play a role in determining who will develop this disease. Some women have predisposing factors; those include family history, age and parity. It is a multifactorial disease and its central pathogenesis seems to involve in the systemic activation and injury of maternal endothelial cells, which is manifested by raised blood pressure, proteinuria, accumulation response, systemic inflammatory response and accumulation of anti-angiogenic factors, which causes the 
disease by depriving the glomerular endothelial cells of essential growth factors. Termination of pregnancy may reverse the clinical manifestations of the disease, which suggests that the trophoblastic invasion plays a major role in the pathogenesis of preeclampsia. ${ }^{5}$ In a recent multicentric study, nearly $28 \%$ of hypertensive disorders in pregnancy cases were due to chronic hypertension and $72 \%$ were due to preeclampsia and gestational hypertension. ${ }^{6}$

This disease is associated with maternal and foetal outcome, but very few studies have explored this study. ${ }^{7}$ This prospective study is to know the incidence of the disorders and associated risk factors and to assess the maternal and perinatal outcome in cases of hypertensive disorders in pregnancy.

\section{MATERIALS AND METHODS}

The prospective case-control study was carried over 1 year from February 2014 to January 2015 in the Department of Obstetrics and Gynaecology at Princess Esra Hospital. A total Analysis was carried out on 140 patients. Patients were further classified according to the National High Blood Pressure Education Working Group (NHBPEP) (2000) as having Gestational hypertension (83 cases), mild preeclampsia (38 cases), severe preeclampsia (13 cases) and eclampsia ( 6 cases). The women enrolled had a gestational age of 20-40 weeks; 40 healthy pregnant non-hypertensive women were enrolled into the study as controls. Study was approved by Institute Review Board of Deccan College of Medical Sciences.

Blood pressure was measured using a mercury sphygmomanometer every $4^{\text {th }}$ hourly in a patient with mild preeclampsia and severe preeclampsia and every hourly in a patient with eclampsia with the procedure undertaken on the patient's right arm with an appropriately sized cuff and the patient should be in a seated position.8,9 Diagnostic criteria for preeclampsia are systolic blood pressure of $140 \mathrm{mmHg}$ or more or diastolic blood pressure of $90 \mathrm{mmHg}$ or more on two occasions, at least $6 \mathrm{hrs}$. apart. 10

An increase of $30 \mathrm{mmHg}$ systolic or $15 \mathrm{mmHg}$ diastolic from baseline is no longer diagnostic for preeclampsia, because similar increases are common in uncomplicated pregnancies. Assessment of oedema was done clinically by applying thumb pressure over the medial malleolus and by direct ophthalmoscopy to see any retinal changes (papillae oedema, exudates, haemorrhages and blurring of disc) associated with hypertension were noted.

Patients with pre-existing renal disease, hypertension, diabetes mellitus, gestational hypertension, active urinary tract infection or patients who has refused to cooperate with the study were excluded.

Data was collected and analysed. Gestational age, demographic characteristics, blood pressure recording on admission, biochemical parameters (including complete haematology, biochemistry, 24 hrs. urine protein), ultrasonography of abdomen and foetal wellbeing, complications during hospital stay, maternal and foetal outcome were recorded. The renal complications (proteinuria, hyperuricaemia and acute renal failure) were recorded for individual patients. Blood pressure and labour progress was strictly monitored. All the patients were given antihypertensive drugs; and however, in mild preeclampsia cases the patients were provided Methyldopa and in severe preeclampsia the patients were given Labetalol. Methyldopa is considered to be safe drug for both mother and foetus according to US Food and Drug Administration category B. Labetalol is considered to be category $\mathrm{C}$ drug as per Food and Drug Administration, and is given in cases of severe preeclampsia and eclampsia. Magnesium sulphate is given according to zuspan regimen to control convulsions in patients with eclampsia along with fluid replacement and in addition patients with eclampsia were monitored intensively. All patients were followed-up till 12-weeks postpartum.

\section{RESULTS}

Analysis was carried out on data for 140 patients. There were 83 cases of gestational hypertension (59.28\%), 38 cases of mild preeclampsia (27.14\%), 13 cases of severe preeclampsia (9.28\%) and 6 cases of eclampsia (4.28\%). Table 1 shows that the majority of patients were in the $<25$ years' age group; 44 patients in this earlier age group had gestational HTN, 21 patients in this age group had mild preeclampsia, 7 had severe preeclampsia and 4 had eclampsia.

The major control patients $(57.5 \%)$ were of middle socioeconomic status. In that gestational HTN (61.4\%), mild preeclampsia (55.26\%), severe preeclampsia $(61.23 \%)$ and eclampsia group (83.3\%) were also of middle socioeconomic status (based on Kuppuswamy's socioeconomic status classification (updated in 2012).10,11

More than half of the patients (67.85\%) were primigravida, while the remaining (32.14\%) were multigravida. In the control group, $40 \%$ were primigravida. Mean systolic blood pressure was $118.84 \mathrm{mmHg}$ in the control group, $145.32 \pm 9.7 \mathrm{mmHg}$ in mild preeclampsia group, $160.88 \pm 8.3 \mathrm{mmHg}$ in severe preeclampsia group and $156.89 \pm 9.5 \mathrm{mmHg}$ in the eclampsia group. The difference was statistically significant between the study and the control group (P, 0.0001). Similarly, mean diastolic BP was $79.42 \pm 6.8$ $\mathrm{mmHg}$ in the control group, $93.72 \pm 5.2 \mathrm{mmHg}$ in mild preeclampsia group, $103.25 \pm 7.6 \mathrm{mmHg}$ in severe preeclampsia group and $101.20 \pm 7.9 \mathrm{mmHg}$ in eclampsia group. The difference was statistically significant between the study and control groups (P, 0.0001) (Table 1).

The most common complication was oedema, which was seen in $85.7 \%$ of patients. In our study, proteinuria $\geq 300$ $\mathrm{mg} / 24$ hours was seen in $25.76 \%$ of cases and of $\geq 2 \mathrm{~g} / 24$ hours was seen in $47.1 \%$ of cases. Slightly, one-quarter of cases $(24.2 \%)$ had urine protein excretion of $3-5 \mathrm{~g}$ for 24 hours. There was central nervous system involvement in $7.1 \%$ of cases, elevated bilirubin level in $1.4 \%$, visual symptoms in $2.8 \%$, vaginal bleeding in $6.4 \%$ and HELLP syndrome in $0.7 \%$ (Table 2).

Maximum maternal complications were found in severe preeclampsia group than in eclampsia and mild preeclampsia groups (Table 3). One patient (2.5\%) had acute renal failure in severe preeclampsia group and placental abruption was reported in 1 (2.63\%) cases of preeclampsia, 2 (15.38\%) cases of severe preeclampsia and $1(16.6 \%)$ case of eclampsia (Table 3). Postpartum eclampsia was reported in following cases - 1 $(2.63 \%)$ case of mild preeclampsia and $1(7.6 \%)$ case of severe eclampsia which contributes to $1.42 \%$ of hypertensive disorders in pregnancy cases in our study.

Most normal deliveries occurred in the gestational HTN group (66.26\%), whereas most caesarean sections were undertaken in patients in the eclampsia group (83.3\%). 
Majority of the babies delivered at term, i.e. $76.42 \%$ and $23.57 \%$ delivered preterm.

The adverse neonatal events that has occurred in the various study groups and controls are shown in Tables 5 . Majority of the babies requiring resuscitation were born to patients with eclampsia (45.4\%) followed with those with severe preeclampsia $(17.94 \%)$, mild preeclampsia $(12.1 \%)$ and a very few controls (2.5\%). During hospital admission $3.5 \%$ of babies were stillborn, of whom $1.3 \%$ were born to patients with mild preeclampsia, $2.5 \%$ to patients with severe preeclampsia and $12 \%$ to patients with eclampsia. In the hypertensive disorders in pregnancy groups, $18.51 \%$ of babies were born with an Apgar score, 7 compared with 10\% of babies in the control group. Further, $19.25 \%$ of neonates born to women in the hypertensive disorder groups required resuscitation, whereas only $2.5 \%$ of neonates born to women in the control group required resuscitation and $40 \%$ required NICU admission, whereas only $10 \%$ of neonates born to women in the control group required NICU admission. The overall neonatal mortality rate was $7.8 \%$. Majority of neonatal deaths occurred in the eclampsia group (50\%) (Table 5).

\begin{tabular}{|c|c|c|c|c|c|}
\hline & $\begin{array}{l}\text { Control } \\
(n=40)\end{array}$ & $\begin{array}{c}\text { Gest. HTN } \\
(n=83)\end{array}$ & $\begin{array}{l}\text { Mild Preeclampsia } \\
(n=38)\end{array}$ & $\begin{array}{c}\text { Severe Preeclampsia } \\
(n=13)\end{array}$ & $\begin{array}{c}\text { Eclampsia } \\
(n=6)\end{array}$ \\
\hline \multicolumn{6}{|c|}{ Age } \\
\hline$<25$ yrs. & $25(62.5 \%)$ & $44(53.01 \%)$ & $21(55.26 \%)$ & $7(53.84 \%)$ & $4(66.6 \%)$ \\
\hline $25-30$ yrs. & $10(25 \%)$ & $26(31.32 \%)$ & $12(31.57 \%)$ & $4(30.76 \%)$ & $2(33.3 \%)$ \\
\hline$>30$ yrs. & $5(12.5 \%)$ & $13(15.66 \%)$ & $5(13.15 \%)$ & $2(15.38 \%)$ & 0 \\
\hline \multicolumn{6}{|l|}{ Gravid } \\
\hline Primi & $16(40 \%)$ & $54(65.06 \%)$ & $29(76.31 \%)$ & $8(61.53 \%)$ & $4(66.6 \%)$ \\
\hline Multi & $24(60 \%)$ & $29(34.93 \%)$ & $9(23.68 \%)$ & $5(38.46 \%)$ & $2(33.3 \%)$ \\
\hline \multicolumn{6}{|c|}{ Socio-Economic Status } \\
\hline Low & $17(42.5 \%)$ & $32(38.55 \%)$ & $17(44.73 \%)$ & $5(38.46 \%)$ & $1(16.6 \%)$ \\
\hline Medium & $23(57.5 \%)$ & $51(61.4 \%)$ & $21(55.26 \%)$ & $8(61.53 \%)$ & $5(83.3 \%)$ \\
\hline \multicolumn{6}{|c|}{ CNS } \\
\hline $\mathrm{N}$ & $40(100 \%)$ & $83(100 \%)$ & $75(100 \%)$ & $40(100 \%)$ & $4(66.6 \%)$ \\
\hline $\mathrm{Ab}$ & 0 & & 0 & 0 & $2(33.3 \%)$ \\
\hline \multicolumn{6}{|c|}{ HTN mmHg } \\
\hline Mean SBP & $118.84 \pm 4.7$ & $144.84 \pm 6.6$ & $145.32 \pm 9.7$ & $159.88 \pm 8.3$ & $\begin{array}{c}156.89 \pm 9.5 \\
0\end{array}$ \\
\hline $\begin{array}{l}\text { Mean } \\
\text { DBP }\end{array}$ & $78.42 \pm 6.8$ & $97.99 \pm 6.9$ & $93.72 \pm 5.2$ & $103.25 \pm 7.6$ & $101.20 \pm 7.9$ \\
\hline \multicolumn{6}{|c|}{ Table 1: Demog } \\
\hline
\end{tabular}

\begin{tabular}{|c|c|c|}
\hline CF & Patients (n) & \% \\
\hline HTN & 140 & $100 \%$ \\
\hline Oedema & 120 & $85.7 \%$ \\
\hline Proteinuria & & $25.14 \%$ \\
\hline$\geq 300 \mathrm{mg} / \mathrm{dL}$ & 38 & $9.28 \%$ \\
\hline$\geq 2 \mathrm{~g} / \mathrm{dL}$ & 13 & $7.1 \%$ \\
\hline CNS & 10 & $1.4 \%$ \\
\hline Jaundice & 2 & $2.8 \%$ \\
\hline Visual symptoms & 4 & $6.4 \%$ \\
\hline Vaginal bleeding & 9 & $0.7 \%$ \\
\hline HELLP syndrome & 1 & \\
\hline
\end{tabular}

\begin{tabular}{|c|c|c|c|c|c|}
\hline & $\begin{array}{c}\text { Controls } \\
(n=40)\end{array}$ & $\begin{array}{l}\text { Gest. HTN } \\
(\mathrm{N}=83)\end{array}$ & $\begin{array}{c}\text { Mild } \\
\text { Preeclampsia } \\
(n=38)\end{array}$ & $\begin{array}{l}\text { Severe Preeclampia } \\
\qquad(n=13)\end{array}$ & $\begin{array}{c}\text { Eclampsia } \\
(n=6)\end{array}$ \\
\hline \multicolumn{6}{|c|}{ ANTENATALLY } \\
\hline ARF & 0 & 0 & 0 & 1 & 0 \\
\hline Abruptio & 0 & 0 & $1(2.63 \%)$ & $2(15.38 \%)$ & $1(16.6 \%)$ \\
\hline Cardiovascular Accidents & 0 & 0 & 0 & 0 & 0 \\
\hline Chronic HTN & 0 & 0 & $1(2.63 \%)$ & $3(23.07 \%)$ & $1(16.6 \%)$ \\
\hline Pulmonary Embolism & 0 & 0 & 0 & 0 & 0 \\
\hline Death & 0 & 0 & 0 & 0 & 0 \\
\hline \multicolumn{6}{|c|}{ POST NATALLY } \\
\hline Post-partum Eclampsia & 0 & 0 & $1(2.63 \%)$ & $1(7.6 \%)$ & 0 \\
\hline $\mathrm{PPH}$ & $2(5 \%)$ & 0 & $5(13.15 \%)$ & $7(53.84 \%)$ & $4(66.6 \%)$ \\
\hline
\end{tabular}




\begin{tabular}{|c|c|c|c|c|c|c|}
\hline MOD & $\begin{array}{c}\text { Controls } \\
(\mathbf{n = 4 0 )}\end{array}$ & $\begin{array}{c}\text { Gest. HTN } \\
(\mathbf{N}=\mathbf{8 3})\end{array}$ & $\begin{array}{c}\text { Mild } \\
\text { Preeclampsia } \\
(\mathbf{n = 3 8 )}\end{array}$ & $\begin{array}{c}\text { Severe } \\
\text { Preeclampia } \\
(\mathbf{n = 1 3 )}\end{array}$ & $\begin{array}{c}\text { Eclampsia } \\
(\mathbf{n = 6})\end{array}$ & Total (n=140) \\
\hline Normal & $31(77.5 \%)$ & $55(66.26 \%)$ & $24(63.15 \%)$ & $8(61.53 \%)$ & $1(16.6 \%)$ & $88(62.85 \%)$ \\
\hline Instrumental & 0 & 0 & $1(2.6 \%)$ & 0 & 0 & $1(0.7 \%)$ \\
\hline LSCS & $9(22.5 \%)$ & $28(33.73 \%)$ & $14(36.84 \%)$ & $5(38.46 \%)$ & $5(83.3 \%)$ & $52(37.14 \%)$ \\
\hline \multicolumn{7}{|c|}{ TERM/PRETERM } \\
\hline$<37$ weeks GA & $3(7.5 \%)$ & $13(15.6 \%)$ & $9(23.68 \%)$ & $7(53.84 \%)$ & $4(66.6 \%)$ & $33(23.57 \%)$ \\
\hline$\geq 37$ weeks GA & $27(67.5 \%)$ & $70(84.3 \%)$ & $29(76.31 \%)$ & $6(46.15 \%)$ & $2(33.3 \%)$ & $107(76.42 \%)$ \\
\hline \multicolumn{7}{|c|}{ Table 4: Mode of Delivery and Maternal Outcome } \\
\hline
\end{tabular}

\begin{tabular}{|c|c|c|c|c|c|c|}
\hline & $\begin{array}{c}\text { Controls } \\
(\mathbf{n = 4 0 )}\end{array}$ & $\begin{array}{c}\text { Gest. HTN } \\
\mathbf{( N = 8 3 )}\end{array}$ & $\begin{array}{c}\text { Mild } \\
\text { Preeclampsia } \\
(\mathbf{n = 3 8 )}\end{array}$ & $\begin{array}{c}\text { Severe } \\
\text { Preeclampia } \\
(\mathbf{n = 1 3 )}\end{array}$ & $\begin{array}{c}\text { Eclampsia } \\
(\mathbf{n = 6 )}\end{array}$ & $\begin{array}{c}\text { Total } \\
(\mathbf{n = 1 4 0 )}\end{array}$ \\
\hline IUD & 0 & 0 & $1(2.6 \%)$ & $1(7.6 \%)$ & $1(16.6 \%)$ & $3(2.14 \%)$ \\
\hline Stillborn & 0 & 0 & $1(2.6 \%)$ & $1(7.6 \%)$ & $3(50 \%)$ & $5(3.5 \%)$ \\
\hline Live Births & & $(\mathrm{n}=83)$ & $(\mathrm{n}=36)$ & $(\mathrm{n}=11)$ & $(\mathrm{n}=2)$ & $(\mathrm{n}=132)$ \\
\hline Apgar $<7$ & $4(10 \%)$ & $24(28.9 \%)$ & $9(25 \%)$ & $4(36.3 \%)$ & $1(50 \%)$ & $38(28.78 \%)$ \\
\hline Apgar $>7$ & $36(90 \%)$ & $59(71.08 \%)$ & $27(75 \%)$ & $7(63.6 \%)$ & $1(50 \%)$ & $94(71.21 \%)$ \\
\hline $\begin{array}{c}\text { NICU } \\
\text { admission }\end{array}$ & $4(10 \%)$ & $29(34.9 \%)$ & $10(27.7 \%)$ & $7(63.6 \%)$ & $2(100 \%)$ & $48(36.3 \%)$ \\
\hline $\begin{array}{c}\text { Neonatal } \\
\text { death }\end{array}$ & 0 & 0 & $1(2.7 \%)$ & $1(9.09 \%)$ & $1(50 \%)$ & $3(2.27 \%)$ \\
\hline $\begin{array}{c}\text { Perinatal } \\
\text { Mortality }\end{array}$ & 0 & 0 & $3(2.1 \%)$ & $3(2.1 \%)$ & $5(3.5 \%)$ & $11(7.8 \%)$ \\
\hline \multicolumn{7}{|c|}{ Table 5: Neonatal Outcome } \\
\hline
\end{tabular}

\section{DISCUSSION}

Analysis was carried out on 140 cases (83 gestational HTN cases, 38 mild preeclampsia cases, 13 severe preeclampsia cases and 6 eclampsia cases) and 30 controls. Upon screening 1850 pregnant women, hypertensive disorders of pregnancy were found in $7.56 \%$. HDP has been reported in $6 \%-8 \%$ of pregnancies and may affect as many as $20 \%$ of pregnancies. Similarly, compared to an Indian study, the incidence of preeclampsia was reported to be $8 \%-10 \% .^{12}$ Prakash et al reported preeclampsia in $5.8 \%$ pregnant women. ${ }^{11}$ In the present study, of the 140 cases 83 cases of gestational hypertension $(59.28 \%), 38$ cases of mild preeclampsia (27.14\%), 13 cases of severe preeclampsia (9.28\%) and 6 cases of eclampsia (4.28\%).

Young age and first pregnancy are known to be the risk factors for development of preeclampsia. In this study, the ages of study group subjects were similar to those of controls. The most common manifestation in our study was oedema, which is a very common symptom seen in $80 \%$ of normal pregnancies. The next most common manifestation was proteinuria. This may be due to glomerular involvement, which results in reduction of glomerular filtration rate and proteinuria. ${ }^{13}$ It has been found, however, that hypertension and proteinuria may be absent in $10 \%-15 \%$ of patients who develop HELLP syndrome and in $38 \%$ of patients those who develop eclampsia.

In our study, proteinuria of $\geq 300 \mathrm{mg} / 24$ hours was seen in $25.14 \%$ of cases and proteinuria of $\geq 2 \mathrm{~g} / 24$ hours was reported in $9.28 \%$ of cases. ${ }^{13,14}$

The majority of patients in the group were of medium socioeconomic status. These patients were largely illiterate and deprived of antenatal care. In most patients with preeclampsia, the condition remains asymptomatic so the diagnosis of preeclampsia is missed.
In an another study, it was reported that proteinuria disappeared in all patients over an average time of 32.6 days (10-90 days postpartum) and in another that it resolved in 35.8 days (21-90 days postpartum). Similarly, in our study proteinuria disappeared in an average of 32.6 days (10-90 days postpartum). ${ }^{15}$

Clinical acute renal failure occurred in one patient (2.5\%), whereas in other study the incidence of acute renal failure has varied from $4 \%$ to $23 \% .{ }^{16,17,18}$ Abruptio placentae was reported in $2.85 \%$ of cases, chronic HTN in $3.5 \%$ of cases, Postpartum eclampsia in $1.42 \%$ of cases and PPH was reported in $11.42 \%$ of cases in our current study. Abdella et al in a retrospective study reported the incidence of abruption was highest with eclampsia (23.6\%) followed by chronic HTN (10\%) and preeclampsia (2.3\%).19,20

Most of the central nervous system involvement was found in patients in the eclampsia group. Neurological abnormality was found in $7.1 \%$ of cases and $2.8 \%$ of patients complained of blurred vision and following fundus examination $13.30 \%$ of patients were found to have an abnormal funduscopic changes. Arteriolar attenuation was the most common finding present in $4.5 \%$ of cases and HELLP syndrome was reported in $0.7 \%$ cases. The incidence of HELLP syndrome is $2 \%-12 \%$ in preeclampsia. 19,20

HELLP syndrome may develop in the antepartum as well as postpartum periods. In postpartum period the time of onset ranges from a few hours to 7 days, but the majority of patients develop HELLP syndrome within 48 hours. Conservative treatment is recommended in order to delay the time of delivery. In the present study, HELLP syndrome was observed in $0.7 \%$ of patients in the preeclampsia group. Prakash et al reported HELLP syndrome in $7.5 \%$ of cases of preeclampsia. However, the true incidence of this syndrome is not known because of the differences in diagnostic criteria. ${ }^{20}$ 
Hyperuricaemia was found in $94 \%$ of patients with hypertensive disorders in pregnancy in our study. In normal pregnancy, serum uric acid level decreases $(2.5-4.5 \mathrm{mg} / \mathrm{dL})$ due to plasma volume expansion. Serum creatinine and blood urea are important predictors for renal injury. In our study, levels of these predictors were found to be normal in the control group and raised in all the study groups. The highest values were found in the group with severe preeclampsia suggesting the highest likelihood of kidney injury in this group. Serum bilirubin is rarely increased in patients with preeclampsia, but when elevated indirect fraction predominates suggesting haemolysis related elevation of bilirubin. A rise in serum bilirubin associated with increased serum LDH ( $600 \mathrm{U} / \mathrm{L}$ ) is highly suggestive of HELLP syndrome. In our study, we observed an increase in serum bilirubin levels above the normal level for pregnancy $(1.2 \mathrm{mg} / \mathrm{dL})$. Serum bilirubin was raised in $1.4 \%$ of patients. Liver enzymes (serum glutamic oxaloacetic transaminase, serum alkaline phosphatase and serum glutamate pyruvate transaminase) were significantly increased in all HDP groups. Rise in serum LDH level was observed in all study groups, but more so in the severe preeclampsia.

Outcome was measured by various complications, term delivery or preterm delivery and mode of delivery. Many $(76.52 \%)$ of the women with hypertensive disorders delivered at term compared with $67.5 \%$ women in control group and the rest of $23.48 \%$ delivered preterm compared with $7.5 \%$ women in the control group. Many of the women (55.9\%) with hypertensive disorders in pregnancy had normal vaginal deliveries and compared with $77.5 \%$ of women in the control group. Operative intervention was common with hypertensive disorders with lower segment caesarean sections undertaken in $42.8 \%$ of hypertensive disorders patients versus $22.5 \%$ of control subjects. None of the women in the control group had an instrumental delivery compared with $1.3 \%$ of women who needed forceps or vacuum delivery in mild preeclampsia in the hypertensive disorder group. Yadav et al reported preterm deliveries in $27.8 \%,{ }^{20}$ which is comparable to our study.

Foetal and neonatal outcome was measured in terms of prevalence of Foetal Growth Restriction (FGR), Apgar score and/or admission to a Neonatal Intensive Care Unit (NICU), and stillbirths and neonatal deaths. Neonatal deaths occurred mostly in the eclampsia group, i.e. affecting $50 \%$ of births in that group. Incidence of foetal growth retardation was found in $15.50 \%$ of births, stillbirths in $3.5 \%$ and $2.27 \%$ of neonates overall died. Yadav et al reported stillbirths in $4.8 \%$ and $14.8 \%$ overall perinatal mortality. ${ }^{20}$ Perloff et al reported that perinatal mortality in preeclampsia is 5 -fold higher than normal perinatal mortality and this increases to $20 \%$ in infants of women with eclampsia, ${ }^{21}$ which is comparable to our study. In our study, $28.78 \%$ of neonates born to women in the hypertensive disorder group had an Apgar score 7 compared with $10 \%$ in the control group. Further, $40 \%$ of the neonates required hospital admission compared with only $10 \%$ in the control group.

\section{CONCLUSION}

Total 1900 pregnant women screened in one-year period, amongst them 50 were lost for followup and 1850 were screened, hypertensive disorders was reported in $7.56 \%$ and acute renal failure occurred in 1 case. No maternal mortality was found in our study than compared with previous Indian studies where maternal mortalities were reported, which might be due to the increased number of prompt deliveries with magnesium sulphate therapy and good intensive care. The incidence of adverse foetal outcome was found to be higher in hypertensive pregnant women than in nonhypertensive pregnant women.

However, incidence of stillbirth (3.5\%) in our study is also less comparative to previous other studies. Hence, for good intensive care monitoring in addition to labour monitoring and safe delivery is required for a better outcome in cases of severe preeclampsia and eclampsia; and there is a need to strengthen the neonatal intensive care units and to increase patient awareness for the importance of antenatal checkups from early pregnancy to prevent complications.

\section{REFERENCES}

1. Prakash J, Pandey LK, Singh AK, et al. Hypertension in pregnancy: hospital based study. J Assoc Physicians India 2006;54:273-8.

2. Sibai BM, Mercer B, Sarinoglu C. Severe preeclampsia in the second trimester: recurrence risk and long-term prognosis. Am J Obset Gynecol 1991;165(5 Pt 1):140812.

3. Barton JR, O'brien JM, Bergauer NK, et al. Mild gestational hypertension remote from term: progression and outcome. Am J Obstet Gynecol 2001;184(5):979-83.

4. Sibai BM, Sarinoglu C, Mercer BM. Eclampsia VII pregnancy outcome after eclampsia and long-term prognosis. Am J Obstet Gynecol 1992;166(6 Pt 1):175761, discussion 1761-3.

5. Maynard SE, Min JY, Merchan J, et al. Excess placental soluble fms like tyrosine kinase 1 (sFlt1) may contribute to endothelial dysfunction, hypertension, and proteinuria in preeclampsia. J Clin Invest 2003;111(5):649-58.

6. Matthys LA, Coppage KH, Lambers DS, et al. Delayed postpartum preeclampsia: an experience of 151 cases. Am J Obstet Gynecol 2004;190(5):1464-6.

7. Pennington KA, Schlitt JM, Jackson DL, et al. Preeclampsia: multiple approaches for a multifactorial disease. Dis Model Mech 2012;5(1):9-18.

8. Report of the national high blood pressure education program working group on high blood pressure in pregnancy. Am J Obstet Gynecol 2000;183(1):S1-S22.

9. Kumar N, Gupta N, Kishore J. Kuppuswamy's socioeconomic scale: updating income ranges for the year 2012. Indian J Public Health 2012;56(1):103-4.

10. Menon MK. The evolution of the treatment of eclampsia. J Obstet Gynaecol Br Commonw 1961;68:417-26.

11. Prakash J, Vohra R, Pandey LK, et al. Spectrum of kidney diseases in patients with preeclampsia-eclampsia. J Assoc Physicians India 2010;58:543-6.

12. D'Anna R, Baviera G, Giordano D, et al. Second trimester neutrophil gelatinase-associated lipocalin as a potential prediagnostic marker of preeclampsia. Acta Obstet Gynecol Scand 2008;87(12):1370-3.

13. Sibai BM. Diagnosis, controversies, and management of the syndrome of hemolysis, elevated liver enzymes, and low platelet count. Obstet Gynecol 2004;103 (5 Pt 1):981-91. 
14. Douglas KA, Redman CW. Eclampsia in the United Kingdom. BMJ 1994;309(6966):1395-400.

15. Gärtner HV, Sammoun A, Wehrmann $M$, et al. Preeclamptic nephropathy-an endothelial lesion. A morphological study with a review of the literature. Eur J Obstet Gynecol Reprod Biol 1998;77(1):11-27.

16. Mjahed K, Alaoui SY, Barrou L. Acute renal failure during eclampsia: incidence risks factors and outcome in intensive care unit. Ren Fail 2004;26(3):215-21.

17. Peng DZ. Acute renal failure in severe pregnancy induced hypertension: a report of 19 cases. Zhonghua Fu Chan Ke Za Zhi 19932;28(5):281-3, 314.

18. Conrad KP, Lindheimer MD. Renal and cardiovascular alterations. $2^{\text {nd }}$ ed. In: Lindheimer MD, Roberts JM, Cunningham FG, (eds). Chesley's hypertensive disorders in pregnancy. Stamford CT: Appleton and Lange 1999:263-326.
19. Yadav S, Saxena U, Yadav R, et al. Hypertensive disorders of pregnancy and maternal and foetal outcome: a case controlled study. J Indian Med Assoc 1997;95(10): 548-51.

20. Aali BS, Ghafoorian J, Mohamad-Alizadeh S. Severe preeclampsia and eclampsia in kerman, Iran: complications and outcomes. Med Sci Monit 2004;10(4):CR163-7.

21. Sibai BM, Ramadan MK. Acute renal failure in pregnancies complicated by hemolysis, elevated liver enzymes, and low platelets. Am J Obstet Gynecol 1993;168(6 Pt 1):1682-7, discussion 1687-90. 